Check for updates

Cite this: RSC Adv., 2017, 7, 36473

Received 22nd May 2017

Accepted 12th July 2017

DOI: 10.1039/c7ra05744j

rsc.li/rsc-advances

\section{Flexible composite film of aligned polyaniline grown on the surface of magnetic barium titanate/ polyvinylidene fluoride for exceptional microwave absorption performance $\uparrow$}

\begin{abstract}
Lujun Yu, (D) Yaofeng Zhu* and Yaqin Fu
A rational structure design is always an attractive approach for high-performance microwave absorbers. Accordingly, flexible $\mathrm{BaTiO}_{3} @ \mathrm{Ni}-\mathrm{P} /$ polyvinylidene fluoride/polyaniline ( $\left.\mathrm{BaTiO}_{3} @ \mathrm{Ni}-\mathrm{P} / \mathrm{PVDF} / \mathrm{PANI}\right)$ composite films were fabricated by growing aligned PANI on the surface of a $\mathrm{BaTiO}_{3} @ \mathrm{Ni}-\mathrm{P} / \mathrm{PVDF}$ composite film. Morphology and structure characterization showed that uniform core-shell $\mathrm{BaTiO}_{3} @ \mathrm{Ni}-$ $P$ microspheres and the unique conelike shapes of aligned PANI were innovatively fabricated. The effect of the special structure on microwave absorption properties was investigated within the $2-18 \mathrm{GHz}$ frequency range. The prepared absorbents displayed exceptional microwave absorption performances. The minimum reflection of $\mathrm{BaTiO}_{3} @ \mathrm{Ni}-\mathrm{P} / \mathrm{PVDF} / \mathrm{PANI}$ reached $-22.56 \mathrm{~dB}$ at $12.72 \mathrm{GHz}$ with a thickness of $2 \mathrm{~mm}$, and the bandwidth that corresponded to reflection loss below $-10 \mathrm{~dB}$ reached $4.33 \mathrm{GHz}$ (11.12-15.45 GHz). The possible absorption mechanism of $\mathrm{BaTiO}_{3} @ \mathrm{Ni}-\mathrm{P} / \mathrm{PVDF} / \mathrm{PANI}$ was also studied in detail. Results offer an effective means to develop microwave absorbers via rational microstructure design.
\end{abstract}

\section{Introduction}

Electromagnetic wave (EW) irradiation is an uncontrolled offshoot of the explosive growth of information technology and the widespread use of high-frequency electromagnetic microwaves. ${ }^{1,2} \mathrm{EW}$ irradiation not only influences the operation of electronic devices but also endangers human health. ${ }^{3,4}$ Extensive studies have focused on the development of highperformance microwave absorption materials (MAMs) to solve the EW pollution problem. Interest in ferromagnetic materials, ${ }^{5,6} \mathrm{C}$ materials, ${ }^{7-9}$ and conducting polymers ${ }^{10,11}$ has increased recently.

As a typical dielectric material, barium titanate $\left(\mathrm{BaTiO}_{3}\right)$ has attracted considerable scientific attention due to its remarkable properties, including high dielectric constant, spontaneous polarization, easy preparation and low cost. ${ }^{12,13}$ In particular, $\mathrm{BaTiO}_{3}$ has received extensive attention as an electromagnetic wave absorber given its tremendous dielectric relaxation in the gigahertz frequency bands. Nevertheless, the microwave absorption property of pure $\mathrm{BaTiO}_{3}$ is relatively poor because of its non-magnetic feature. ${ }^{14}$ Therefore, magnetic functionalized

Key Laboratory of Advanced Textile Materials, Manufacturing Technology Ministry of Education, Zhejiang Sci-Tech University, No. 928 Second Avenue XiaSha Higher Education Zone, Hangzhou 310018, P. R. China. E-mail: 201610301016@mails. zstu.edu.cn; fyq01@zstu.edu.cn; yfzhu@zstu.edu.cn; Fax: +86 571 86843607; Tel: +8657186843607

$\dagger$ Electronic supplementary information (ESI) available. See DOI: $10.1039 / \mathrm{c} 7 \mathrm{ra05744j}$
$\mathrm{BaTiO}_{3}$ materials that combine dielectric and magnetic losses have attracted considerable attention and have been extensively studied to improve their microwave absorption performance. ${ }^{15,16}$ Wang et al. fabricated $\mathrm{BaTiO}_{3} / \mathrm{Ni}$ hybrid particles with a minimum reflection loss (RL) of $-14.9 \mathrm{~dB}$ at $13.6 \mathrm{GHz}$, and a frequency bandwidth of $<-5 \mathrm{~dB}$ over nearly the entire $\mathrm{Ku}-$ band with a thickness of $1.2 \mathrm{~mm}^{17}$ Qing et al. prepared $\mathrm{BaTiO}_{3} /$ carbonyl iron composites with a minimum RL of $-42 \mathrm{~dB}$ at 4.1 $\mathrm{GHz}$ and a thickness of $2 \mathrm{~mm} .{ }^{18}$ Yang et al. found that the permittivity and permeability of $\mathrm{BaTiO}_{3} /$ carbonyl iron composites can be tuned by the mass ratio of the components to improve absorption properties. The optimal $\mathrm{RL}$ of $\mathrm{BaTiO}_{3} /$ carbonyl iron composites reached $-24 \mathrm{~dB}$ at around $3.2 \mathrm{GHz}^{19}$ The aforementioned studies show that the complex relative permittivity and permeability of magnetic-functionalized $\mathrm{BaTiO}_{3}$ can be balanced by its complex loss mechanism to improve microwave absorption properties.

Polyaniline (PANI), which was used as a microwave absorption material in previous works, has always been a popular topic because of its advantages of environmental stability and tunable conductivity. ${ }^{20-23}$ PANI-based composites, such as graphene@ $\mathrm{Fe}_{3} \mathrm{O}_{4} @ \mathrm{SiO}_{2} @ \mathrm{PANI},{ }^{24} \mathrm{PANI} / \mathrm{BaFe}_{12} \mathrm{O}_{19} / \mathrm{Y}_{3} \mathrm{Fe}_{5} \mathrm{O}_{12},{ }^{25}$ $\mathrm{Co} / \mathrm{C} / \mathrm{PANI},{ }^{26}$ and graphene foam/PANI ${ }^{27}$ exhibit enhanced microwave absorption properties. To our knowledge, reports regarding aligned PANI composites applied to EW absorbers remain rare.

The cooperative actions of dielectric, magnetic, resistance losses and the novel structure are the key factors that determine 
the microwave absorption properties of absorbers. ${ }^{28-31}$ In consideration of the aforementioned situation, we used a multiphase structure that involved Ni-P-covered $\mathrm{BaTiO}_{3}$ combined with aligned PANI to design flexible polyvinylidene fluoride (PVDF)-based composites. In this study, $\mathrm{BaTiO}_{3} @ \mathrm{Ni}-\mathrm{P} / \mathrm{PVDF} /$ PANI composites were prepared using Ni-P-covered $\mathrm{BaTiO}_{3}$ compound with PVDF via electroless deposition technology and physical mixing. Then, aligned PANI was grown on the surface of the composites via dilute polymerization. The multi-phase structure of the $\mathrm{BaTiO}_{3} @ \mathrm{Ni}-\mathrm{P} / \mathrm{PVDF} / \mathrm{PANI}$ composites can induce different ways to produce loses, and the unique conelike shape of aligned PANI can form dissipation micro-current and long transmission paths to enhance EW energy absorption. In consideration of these views, our findings are promising for microwave absorption materials.

\section{Experimental section}

\subsection{Materials}

$\mathrm{BaTiO}_{3}$ (diameter, $\leq 100 \mathrm{~nm}$ ), $N, N$-dimethyl formamide (DMF, 99.5\%), aniline (99.5\%), ammonium persulfate (APS, 98.0\%), perchloric acid $\left(\mathrm{HClO}_{4}, 70 \%\right), \mathrm{SnCl}_{2}(99.0 \%), \mathrm{PbCl}_{2}(\geq 99.9 \%)$, $\mathrm{NiSO}_{4} \cdot 6 \mathrm{H}_{2} \mathrm{O} \quad(98.5 \%), \quad \mathrm{Na}_{3} \mathrm{C}_{6} \mathrm{H}_{5} \mathrm{O}_{7} \cdot 2 \mathrm{H}_{2} \mathrm{O} \quad(\geq 99.0 \%), \quad \mathrm{H}_{3} \mathrm{BO}_{3}$ $(99.8 \%)$ and $\mathrm{NaH}_{2} \mathrm{PO}_{2} \cdot \mathrm{H}_{2} \mathrm{O}(\geq 99.0 \%)$ were purchased from Aladdin Industrial Corporation. PVDF was purchased from Shanghai 3F Company.

\subsection{Preparation of $\mathrm{BaTiO}_{3} @ \mathrm{Ni}-\mathrm{P}$ core-shell structure}

$\mathrm{BaTiO}_{3}(1.0 \mathrm{~g})$ was sensitized in $\mathrm{SnCl}_{2}(0.08 \mathrm{M})$ solution for $5 \mathrm{~min}$ and then activated in $\mathrm{PdCl}_{2}(0.01 \mathrm{M})$ solution for $5 \mathrm{~min}$ before

Table 1 The components of the electroless deposition solution

\begin{tabular}{llll}
\hline $\begin{array}{l}\text { Nickel } \\
\text { resource }\end{array}$ & $\begin{array}{l}\text { Complexing } \\
\text { agent }\end{array}$ & $\begin{array}{l}\text { Buffer } \\
\text { agent }\end{array}$ & $\begin{array}{l}\text { Reducing } \\
\text { agent }\end{array}$ \\
\hline $\mathrm{NiSO}_{4} \cdot 6 \mathrm{H}_{2} \mathrm{O}$ & $\mathrm{Na}_{3} \mathrm{C}_{6} \mathrm{H}_{5} \mathrm{O}_{7} \cdot 2 \mathrm{H}_{2} \mathrm{O}$ & $\mathrm{H}_{3} \mathrm{BO}_{3}$ & $\mathrm{NaH}_{2} \mathrm{PO}_{2} \cdot \mathrm{H}_{2} \mathrm{O}$ \\
$\left(25 \mathrm{~g} \mathrm{~L}^{-1}\right)$ & $\left(35 \mathrm{~g} \mathrm{~L}^{-1}\right)$ & $\left(30 \mathrm{~g} \mathrm{~L}^{-1}\right)$
\end{tabular}

performing electroless deposition. Subsequently, the pretreated $\mathrm{BaTiO}_{3}$ powder was immersed in an electroless deposition solution ( $\mathrm{pH}=9$ and temperature controlled under $25{ }^{\circ} \mathrm{C}$ ) with constant stirring for $1 \mathrm{~h}$. The components of the electroless deposition solution are listed in Table 1. The BaTiO ${ }_{3} @ N i-P$ powder was obtained by filtering and washing with deionized water. The reaction equation can be described by eqn (1)-(4). The mechanisms of the pretreatment and electroless deposition processes are schematically illustrated in Fig. 1a.

$$
\begin{gathered}
\mathrm{SnCl}_{2}+\mathrm{PdCl}_{2} \rightarrow \mathrm{SnCl}_{4}+\mathrm{Pd} \\
\mathrm{Ni}^{2+}+\mathrm{H}_{2} \mathrm{PO}_{2}{ }^{-}+\mathrm{H}_{2} \mathrm{O} \rightarrow \mathrm{Ni}+2 \mathrm{H}^{+}+\mathrm{H}\left(\mathrm{HPO}_{3}\right)^{-} \\
2 \mathrm{HPO}_{2}^{-}+2 \mathrm{H}_{2} \mathrm{O} \rightarrow 2 \mathrm{H}\left(\mathrm{HPO}_{3}\right)^{-}+\mathrm{H}_{2} \\
\mathrm{H}_{2} \mathrm{PO}_{2}^{-}+2 \mathrm{H}^{+}+\mathrm{e}^{-} \rightarrow 2 \mathrm{H}_{2} \mathrm{O}+\mathrm{P}
\end{gathered}
$$

\subsection{Preparation of $\mathrm{BaTiO}_{3} @ \mathrm{Ni}-\mathrm{P} / \mathrm{PVDF}$ composite}

PVDF powder was dissolved in DMF solution with a mass ratio of $1: 9$ under constant stirring at room temperature for $24 \mathrm{~h}$. Afterward, BaTiO 3 @Ni-P (70 wt\% loaded onto PVDF) was added by stirring into the solution to obtain a uniformly mixed solution. The mixture was then poured into a glass plate and dried in a vacuum oven at $40{ }^{\circ} \mathrm{C}$ for $12 \mathrm{~h}$. Then, the $\mathrm{BaTiO}_{3} @ \mathrm{Ni}-\mathrm{P} /$ PVDF film was obtained. Moreover, the pure PVDF film and the $\mathrm{BaTiO}_{3} / \mathrm{PVDF}$ film were prepared in the same manner.

\subsection{Preparation of $\mathrm{BaTiO}_{3} @ \mathrm{Ni}-\mathrm{P} / \mathrm{PVDF} / \mathrm{PANI}$ composite}

Aligned PANI was grown on the surface of the $\mathrm{BaTiO}_{3} @ \mathrm{Ni}-\mathrm{P} /$ PVDF film through a dilute polymerization process (Fig. 1b). In a typical process, $0.01 \mathrm{M}$ aniline was added to the $\mathrm{HClO}_{4}(1$ M) solution under constant stirring until a homogenous suspension was achieved. Subsequently, the $\mathrm{BaTiO}_{3} @ \mathrm{Ni}-\mathrm{P} /$ PVDF film was introduced into the mixture solution, and then APS aqueous solution ([aniline $] /[$ APS $]=1.5$ ) was added to the suspension. The polymerization process was performed in an ice bath for $12 \mathrm{~h}$ under constant stirring.

(a)

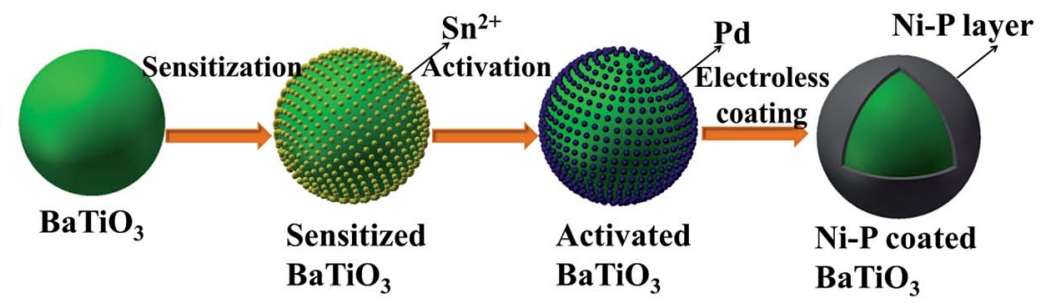

(b)

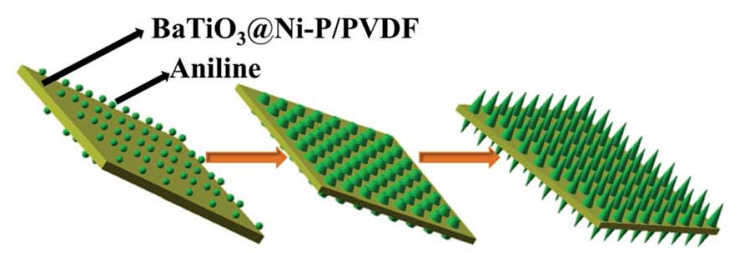

Low concentration nucleation Growth

Fig. 1 Schematic illustration of (a) formation of $\mathrm{Ni}-\mathrm{P}$-coated $\mathrm{BaTiO}_{3}$ and (b) formation of aligned PANI on the surface of the composites. 


\subsection{Characterization}

The morphology of the samples was observed using a field emission scanning electron microscope (Hitachi S-4800) and transmission electron microscope (JEOL JEM-2100F). The crystal structure of the prepared powders was analyzed with an X-ray diffractometer (Bruker AXS, D8-Discover) using $\mathrm{Cu} \mathrm{K} \alpha$ radiation. Fourier transform infrared spectroscopy (FT-IR) was performed using a Nicolet 5700 spectrometer (Thermo Electron Corporation, USA). X-ray photoelectron spectroscopy (XPS) was performed using a K-alpha + photoelectron spectrometer (Thermo Fisher Scientific) to measure the chemical composition and chemical states of the samples. The magnetic properties of the sample in powder form were determined using a model VersaLab vibrating sample magnetometer (VSM, Quantum Design). The composite films (70 wt $\% \mathrm{BaTiO}_{3}$ or $\mathrm{BaTiO}_{3} @ N i-\mathrm{P}$ powder loaded onto PVDF) used for electromagnetic measurements were prepared via a simple hot-molding procedure. The films were collapsed and compressed into wafers for $3 \mathrm{~min}$ at $200{ }^{\circ} \mathrm{C}$ under $5 \mathrm{MPa}$, and toroidally shaped samples $\left(\varphi_{\text {out }}=7 \mathrm{~mm}, \varphi_{\text {inner }}=3.04 \mathrm{~mm}\right)$ were obtained. The coaxial circle sample ( $\left.\mathrm{BaTiO}_{3} @ \mathrm{Ni}-\mathrm{P} / \mathrm{PVDF} / \mathrm{PANI}\right)$ was obtained by growing the aligned PANI on the surface of the coaxial circles of $\mathrm{BaTiO}_{3} @ \mathrm{Ni}-\mathrm{P} / \mathrm{PVDF}$. The effective complex permittivity $\varepsilon_{\mathrm{r}}\left(\varepsilon_{\mathrm{r}}\right.$ $\left.=\varepsilon^{\prime}-\mathrm{j} \varepsilon^{\prime \prime}\right)$ and permeability $\mu_{\mathrm{r}}\left(\mu_{\mathrm{r}}=\mu^{\prime}-\mathrm{j} \mu^{\prime \prime}\right)$ were measured with a vector network analyzer (N5224A, Agilent) within the 2-18 $\mathrm{GHz}$ range.

\section{Results and discussion}

\subsection{Morphology and structure of $\mathrm{BaTiO}_{3} @ \mathrm{Ni}-\mathrm{P}$}

The scanning electron microscopy (SEM) morphologies of pristine $\mathrm{BaTiO}_{3}$ and $\mathrm{BaTiO}_{3} @ \mathrm{Ni}-\mathrm{P}$ are shown in Fig. 2. As shown in Fig. 2a, pristine $\mathrm{BaTiO}_{3}$ has a smooth surface with a diameter of approximately $100 \mathrm{~nm}$, whereas the Ni-P-covered $\mathrm{BaTiO}_{3}$ has a rough surface (Fig. 2b). The insets of Fig. 2a and b show that Ni-P particles adhered uniformly onto the surface of $\mathrm{BaTiO}_{3}$. The elemental composition of $\mathrm{BaTiO}_{3} @ \mathrm{Ni}-\mathrm{P}$ was evaluated using energy-dispersive X-ray spectroscopy (EDS), and the results are shown in Fig. S1. $\dagger$ The presence of $\mathrm{O}, \mathrm{Ti}, \mathrm{Ba}, \mathrm{Ni}$ and $\mathrm{P}$ elements in $\mathrm{BaTiO}_{3} @ \mathrm{Ni}-\mathrm{P}$ particles was observed. The atomic ratios of the electrolessly deposited $\mathrm{Ni}$ and $\mathrm{P}$ reached $10.41 \%$ and $2.27 \%$, respectively.

Fig. 2c and $\mathrm{d}$ show the transmission electron microscopy (TEM) images of $\mathrm{BaTiO}_{3}$ and $\mathrm{BaTiO}_{3} @ \mathrm{Ni}-\mathrm{P}$, respectively. Compared with pure $\mathrm{BaTiO}_{3}$ (Fig. 2c), the Ni-P coated onto the surface of $\mathrm{BaTiO}_{3}$ and the core-shell structure were further confirmed (Fig. 2d). As shown in Fig. 2d, the Ni-P layer comprises dense and loose layers. The difference in compact degree can be attributed to the different catalytic activity centers, which are the absorbed Pd and autocatalytic Ni.

$\mathrm{X}$-ray diffraction (XRD) measurement was performed to investigate the crystal phase structure of the as-prepared $\mathrm{BaTiO}_{3} @ \mathrm{Ni}-\mathrm{P}$. As shown in Fig. 3a, the diffraction peaks
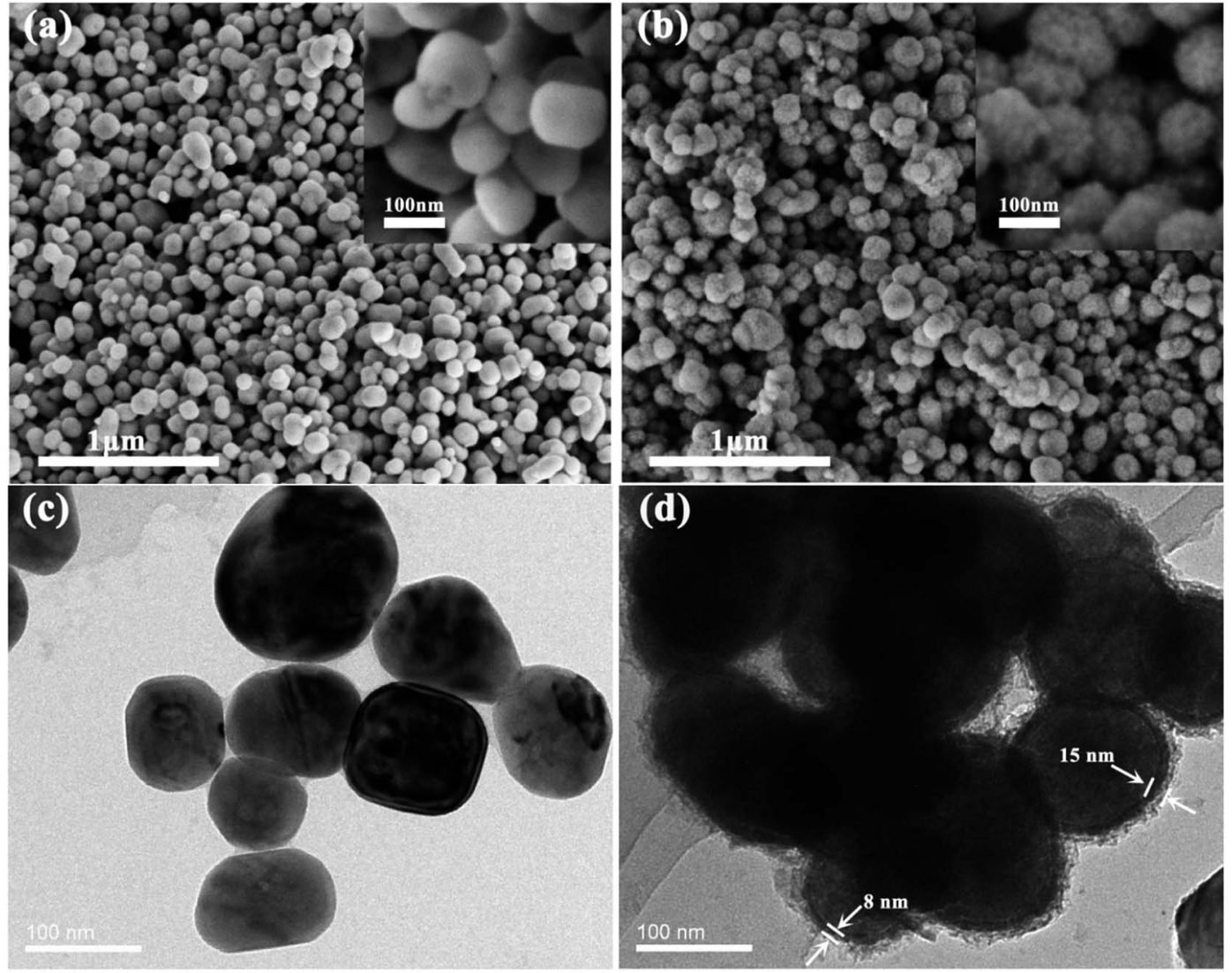

Fig. $2 \mathrm{SEM}$ images of (a) pristine $\mathrm{BaTiO}_{3}$ and (b) $\mathrm{BaTiO}_{3} \mathrm{QNi}-\mathrm{P}$. TEM images of (c) pristine $\mathrm{BaTiO}_{3}$ and (d) $\mathrm{BaTiO} \mathrm{CaNi}_{3}-\mathrm{P}$. 

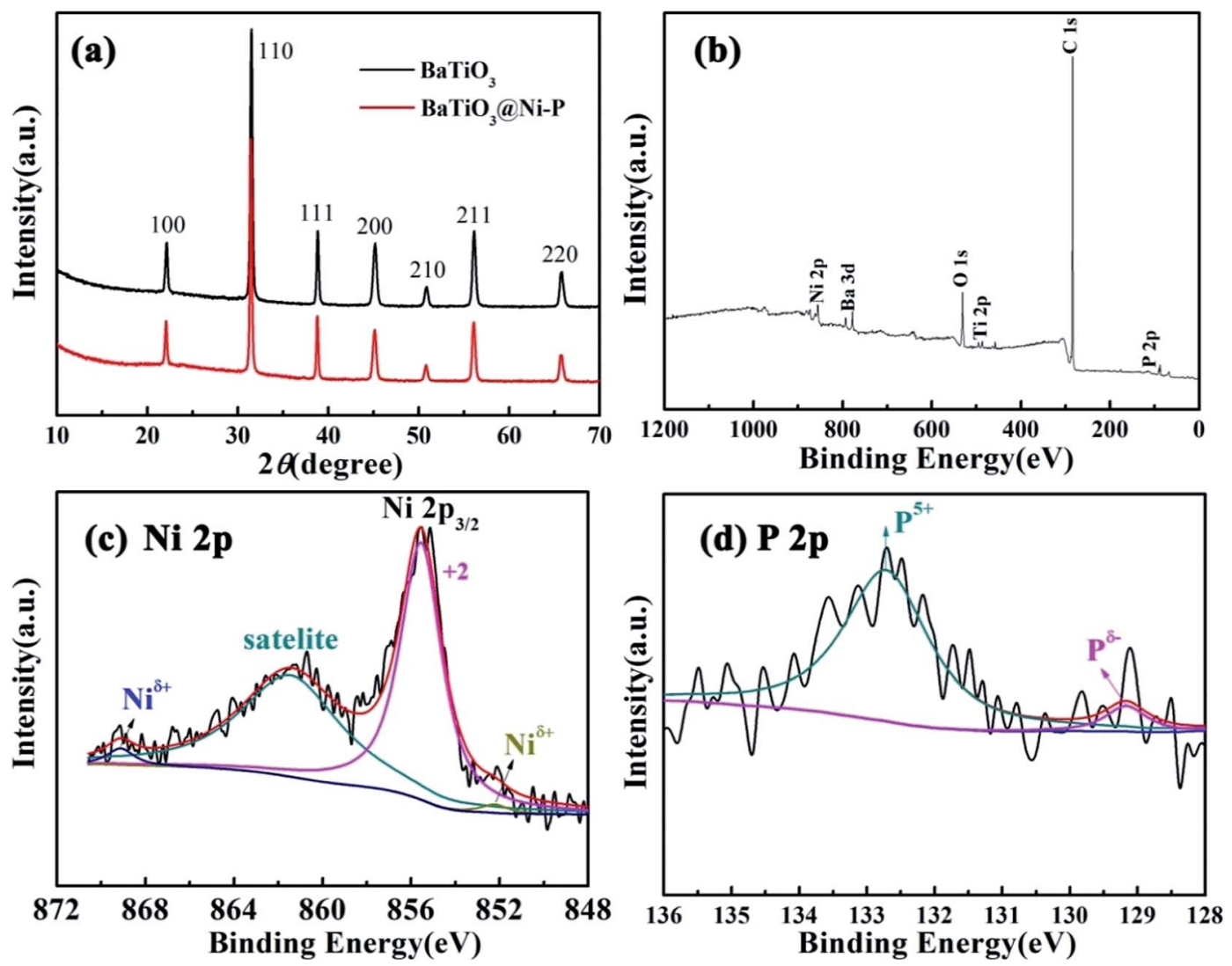

Fig. 3 (a) XRD patterns of the samples. XPS survey spectra of (b) wide scan, peak deconvolution of (c) Ni $2 p$ and (d) P 2p for BaTiO 3 @Ni-P.

located at $2 \theta=22.1^{\circ}, 31.5^{\circ}, 38.8^{\circ}, 45.2^{\circ}, 50.9^{\circ}, 56.1^{\circ}$ and $65.8^{\circ}$ can be indexed to the (100), (110), (111), (200), (210), (211), and (220) planes of $\mathrm{BaTiO}_{3}$, respectively (JCPDS card no. 31-0174). ${ }^{32}$ Nonetheless, no diffraction peak is assigned to Ni-P, which implies that the Ni-P layer is amorphous. XPS was performed to further understand the oxidation state of the amorphous Ni-P layer, and the corresponding results are presented in Fig. 3b-d. The survey spectrum (Fig. 3b) indicates the presence of $\mathrm{Ba}, \mathrm{Ti}, \mathrm{O}$, $\mathrm{Ni}, \mathrm{P}$, and $\mathrm{C}$ from the reference, which is consistent with the result of the EDS analysis. The Ni 2p emission spectrum (Fig. 3c) is the best fitted characteristics of $\mathrm{Ni}^{2+}$, the shakeup satellite, and $\mathrm{Ni}^{\delta+}$ in the $\mathrm{Ni}-\mathrm{P}$ compound. The peak at $855.6 \mathrm{eV}$ is indexed to $\mathrm{Ni}^{2+}$ in nickel oxide. The shakeup satellite at $861.4 \mathrm{eV}$ can be clearly observed at the high binding energy side of the $\mathrm{Ni} 2 \mathrm{p}_{3 / 2}$ edge. Two peaks, i.e., those at $852.2 \mathrm{eV}$ and $869.1 \mathrm{eV}$, are assigned to $\mathrm{Ni}^{\delta+}$ in the Ni-P compound. ${ }^{33-35}$ In the $\mathrm{P} 2 \mathrm{p}$ spectra (Fig. $3 \mathrm{~d}$ ), the peak located at $129.2 \mathrm{eV}$ is attributed to the reduced phosphide (denoted as $\mathrm{P}^{\delta-}$ ). The broad peak at $132.7 \mathrm{eV}$ is assigned to oxidized $\mathrm{P}$ (denoted as $\mathrm{P}^{5+}$ ). ${ }^{35,36}$ All the aforementioned results suggest that the as-prepared $\mathrm{BaTiO}_{3} @ \mathrm{Ni}-\mathrm{P}$ consists of the $\mathrm{Ni}-\mathrm{P}$ form. To identify the magnetic properties of Ni-P, VSM was used at room temperature. The result shows the saturated magnetization $\left(M_{\mathrm{s}}\right)$ of $\mathrm{BaTiO}_{3} @ \mathrm{Ni}-\mathrm{P}$ is $1.61 \mathrm{emu} \mathrm{g}^{-1}$ (Fig. S2 $\dagger$ ).

\subsection{Morphology and structure of $\mathrm{BaTiO}_{3} @ \mathrm{Ni}-\mathrm{P} / \mathrm{PVDF} / \mathrm{PANI}$}

The morphology of the as-prepared $\mathrm{BaTiO}_{3} @ \mathrm{Ni}-\mathrm{P} / \mathrm{PVDF} / \mathrm{PANI}$ is shown in Fig. 4. The surface image (Fig. 4a) and the edge of the cross-sectional image (Fig. 4b) show that vertically aligned PANI with a length of approximately $200 \mathrm{~nm}$ grew on the surface of the PVDF film. The formation process of the aligned PANI is illustrated in Fig. 1b. First, active nucleation sites were generated on the surface of the films. Then, the heterogeneous nucleation of PANI occurred due to the low concentration of aniline during oxidation polymerization. Finally, PANI would further grow along the initial nuclei to form the aligned PANI on the film. ${ }^{37}$ An aligned nanostructure is a well-known cause of multiple reflections of incident EW, and a high amount of EW energy can be converted into thermal energy or other forms of energy. Therefore, such aligned nanostructure can enhance the efficiency of wave absorption and improve microwave absorption properties. The middle of the cross-sectional image (Fig. 4c) and the corresponding elemental mapping further verify that $\mathrm{Ba}, \mathrm{Ti}, \mathrm{O}, \mathrm{Ni}, \mathrm{P}$ and Pd elements are distributed in the $\mathrm{BaTiO}_{3} @ \mathrm{Ni}-\mathrm{P} / \mathrm{PVDF} / \mathrm{PANI}$ film. In addition, the crystalline phase and the chemical structure of the aligned PANI were analyzed via XRD and FT-IR, respectively (Fig. S3†). Interestingly, the PVDF-based composite absorbers exhibit flexible properties (Fig. S4 $\dagger$ ). Therefore, the $\mathrm{BaTiO}_{3} @ \mathrm{Ni}-\mathrm{P} / \mathrm{PVDF} / \mathrm{PANI}$ film is anticipated to have potential practical applications.

\subsection{EW absorption properties of composites}

The microwave absorption performance of an absorber is wellknown to be highly associated with its effective complex permittivity $\left(\varepsilon_{\mathrm{r}}=\varepsilon^{\prime}-\mathrm{j} \varepsilon^{\prime \prime}\right)$ and effective complex permeability 


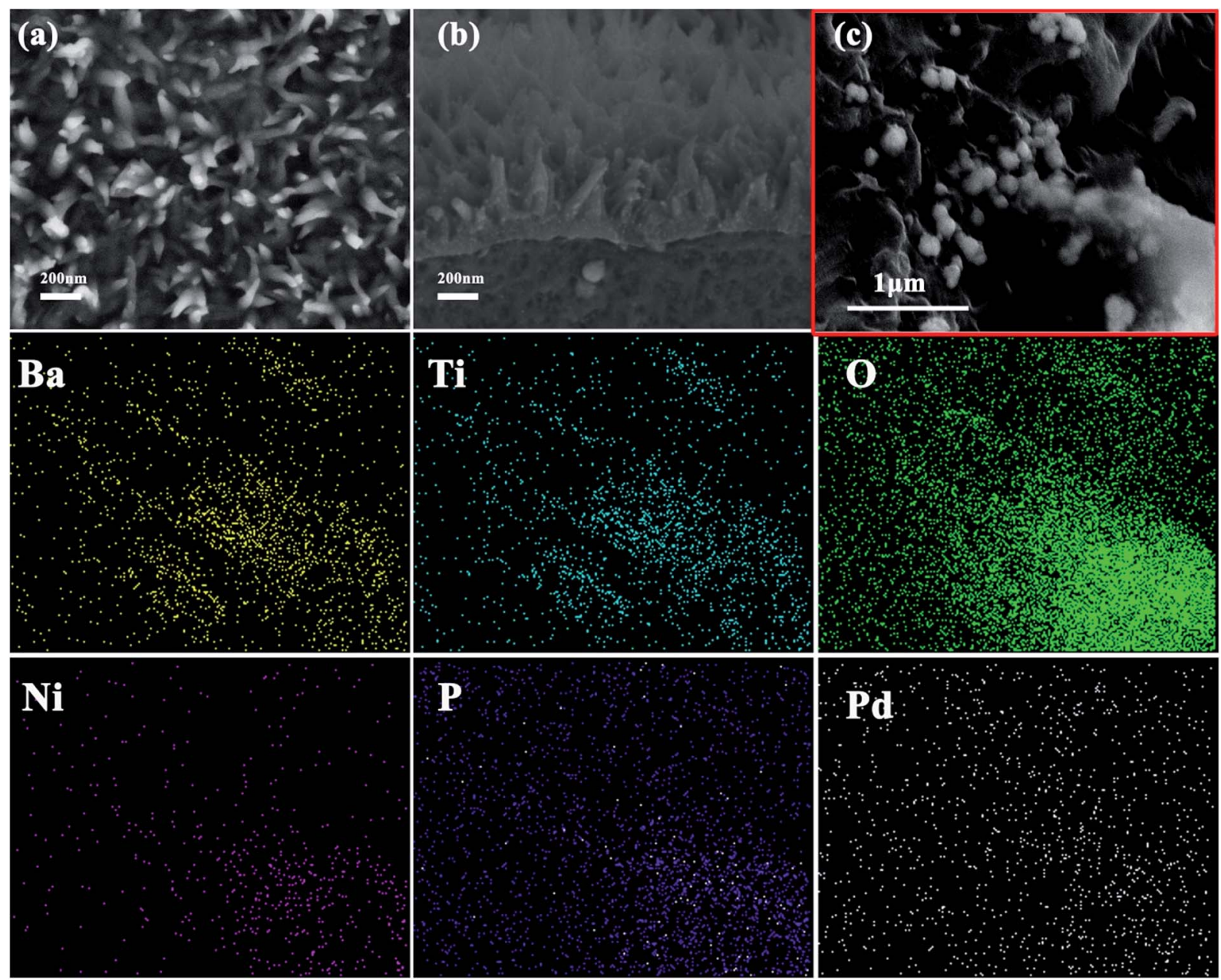

Fig. 4 SEM images of $\mathrm{BaTiO}_{3} @ \mathrm{Ni}-\mathrm{P} / \mathrm{PVDF} / \mathrm{PANI}$ : (a) surface image; (b) edge of the cross-sectional image; (c) middle of the cross-sectional image; and SEM-EDS elemental mappings that correspond to (c): $\mathrm{Ba}, \mathrm{Ti}, \mathrm{O}, \mathrm{Ni}, \mathrm{P}$ and Pd elements.

$\left(\mu_{\mathrm{r}}=\mu^{\prime}-\mathrm{j} \mu^{\prime \prime}\right)$. The real parts of complex permittivity and permeability represent the storage capability of EW energy, whereas the imaginary parts of effective complex permittivity and permeability represent the loss capability of EW energy ${ }^{38}$ Fig. 5a and b show the real part $\left(\varepsilon^{\prime}\right)$ and imaginary part $\left(\varepsilon^{\prime \prime}\right)$ of the effective complex permittivity of the PVDF-based composites within the $2-18 \mathrm{GHz}$ frequency range. The $\varepsilon^{\prime}$ and $\varepsilon^{\prime \prime}$ values of pure PVDF are within the ranges of $2-3$ and $0.2-$ 0.5 , respectively, which are relatively higher than that for the epoxy resin matrix. ${ }^{39}$ Compared with those of $\mathrm{BaTiO}_{3} / \mathrm{PVDF}$, the $\varepsilon^{\prime}$ and $\varepsilon^{\prime \prime}$ values of $\mathrm{BaTiO}_{3} @ \mathrm{Ni}-\mathrm{P} / \mathrm{PVDF}$ are increased over the majority of the $2-18 \mathrm{GHz}$ range. This result indicates that introducing Ni-P can enhance the dielectric constant of $\mathrm{BaTiO}_{3} / \mathrm{PVDF}$, thereby reflecting increased storage and loss capabilities. However, the $\varepsilon^{\prime}$ value of $\mathrm{BaTiO}_{3} @ \mathrm{Ni}-\mathrm{P} / \mathrm{PVDF} /$ PANI mostly declines with the growth of aligned PANI. Notably, the $\varepsilon^{\prime \prime}$ value of $\mathrm{BaTiO}_{3} @ \mathrm{Ni}-\mathrm{P} / \mathrm{PVDF} / \mathrm{PANI}$ exhibits a strong peak within the $7-11 \mathrm{GHz}$ range, which arises from the resonance behavior.

Fig. $5 \mathrm{c}$ and $\mathrm{d}$ show the real part $\left(\mu^{\prime}\right)$ and imaginary part $\left(\mu^{\prime \prime}\right)$ of the effective complex permeability of the composites, respectively. For $\mathrm{BaTiO}_{3} / \mathrm{PVDF}$, the $\mu^{\prime}$ and $\mu^{\prime \prime}$ values are within the range of $0.58-1.59$ and $-1.10-0.22$, respectively. When $\mathrm{BaTiO}_{3}$ was coated with a Ni-P shell, the $\mu^{\prime}$ value is increased in the regions of 8.4-12.3 GHz and 14.1-16.0 GHz. Moreover, the $\mu^{\prime \prime}$ value is improved significantly in the region of $11.9-18 \mathrm{GHz}$. The magnetic properties of $\mathrm{Ni}-\mathrm{P}$ cause this phenomenon, which effectively compensates for the low complex relative permeability of dielectric materials.

Fig. 5e and $\mathrm{f}$ show the dielectric $\operatorname{loss}\left(\tan \delta_{\mathrm{E}}=\varepsilon^{\prime \prime} / \varepsilon^{\prime}\right)$ and magnetic loss $\left(\tan \delta_{\mu}=\mu^{\prime \prime} / \mu^{\prime}\right)$ of the samples. The dielectric losses of $\mathrm{BaTiO}_{3} @ \mathrm{Ni}-\mathrm{P} / \mathrm{PVDF}$ and $\mathrm{BaTiO}_{3} @ \mathrm{Ni}-\mathrm{P} / \mathrm{PVDF} / \mathrm{PANI}$ fluctuate between $0.23-0.75$ and $0.27-0.95$, respectively, which are higher than that for $\mathrm{BaTiO}_{3} / \mathrm{PVDF}$ (i.e., within the ranges of 2-11.3, 12.6-15.5 and 16.3-18 GHz). The magnetic loss of $\mathrm{BaTiO}_{3} @ \mathrm{Ni}-\mathrm{P} / \mathrm{PVDF}$ is higher than those of the other samples within the range of $12-18 \mathrm{GHz}$ and the maximum value reached 0.29 . For a magnetic material, magnetic loss is mainly caused by natural resonance and eddy current loss..$^{39}$ Eddy current loss can be explained by the values of $\mu^{\prime \prime}\left(\mu^{\prime}\right)^{-2} f^{-1}$, which remain constant at various frequencies. By contrast, the fluctuation values indicate that the eddy current effect has an insignificant effect on magnetic loss (as shown in Fig. S5 $\dagger$ ). Therefore, magnetic loss is mainly attributed to natural resonance. 

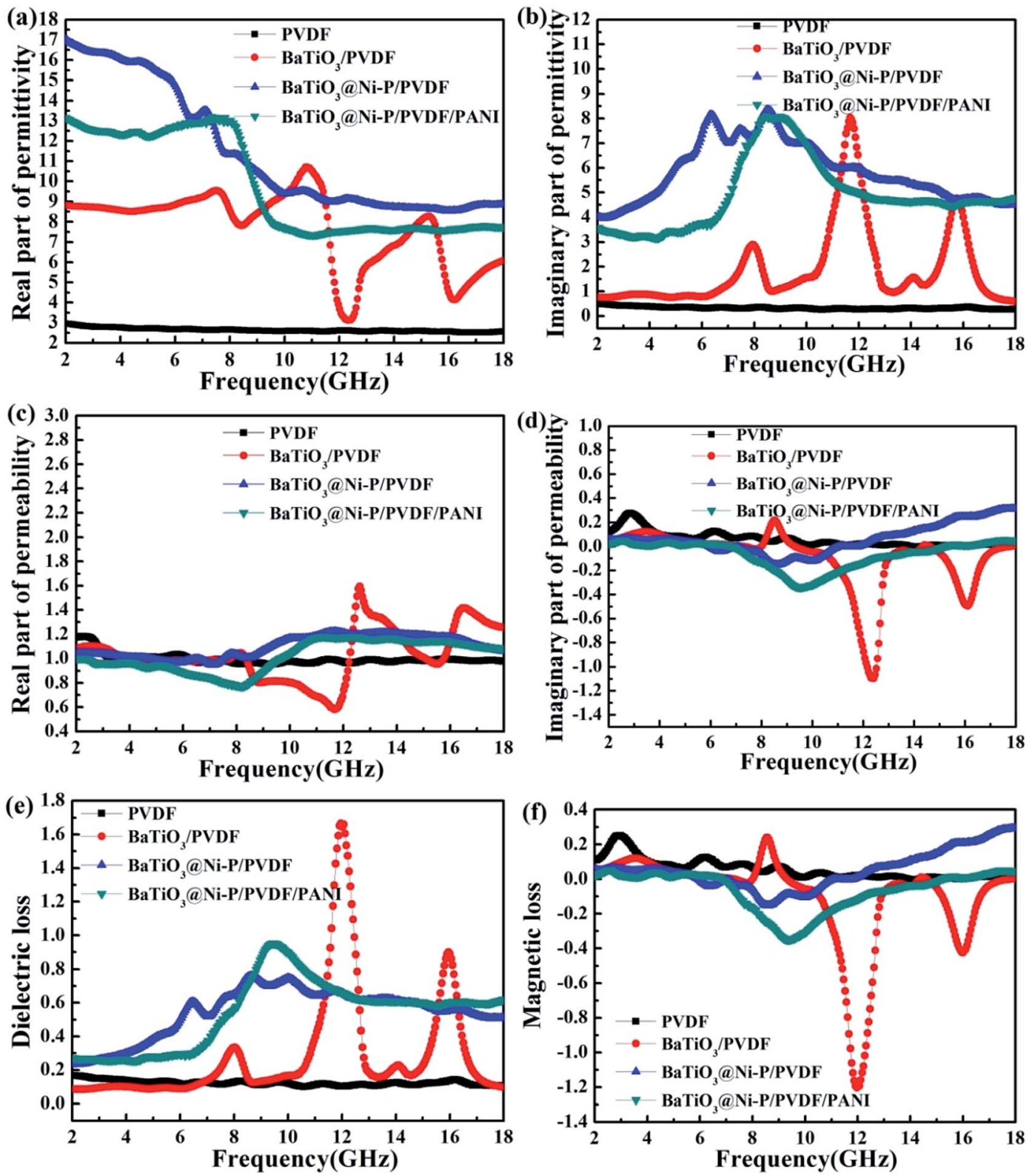

Fig. 5 Complex permittivity of samples: (a) real part and (b) imaginary part. Complex permeability of samples: (c) real part, (d) imaginary part, (e) dielectric loss, and (f) magnetic loss of samples.

The $\varepsilon^{\prime}-\varepsilon^{\prime \prime}$ curves shown in Fig. 6 and $56 \dagger$ illustrate the dielectric loss capability of the samples. Debye dipolar relaxation theory states that each Cole-Cole semicircle corresponds to one Debye relaxation process. For $\mathrm{BaTiO}_{3} @ \mathrm{Ni}-\mathrm{P} /$ PVDF/PANI, two evident Cole-Cole semicircles are found, thereby indicating the existence of a relaxation process. Meanwhile, several semicircles in $\mathrm{PVDF}, \mathrm{BaTiO}_{3} / \mathrm{PVDF}$ and $\mathrm{BaTiO}_{3} @ \mathrm{Ni}-\mathrm{P} / \mathrm{PVDF}$ (Fig. S6 $\dagger$ ) imply that multi-relaxation occurs in the PVDF composites and plays a vital role in EW absorption.

To further clarify the difference in microwave absorption properties, the attenuation constant $\alpha$ and impedance matching properties should also be considered apart from the electromagnetic parameters. The attenuation constant $\alpha$ represents the capability for dielectric and magnetic losses, which are calculated using eqn (5) as follows: ${ }^{40}$

$$
\alpha=\frac{\sqrt{2} \pi f}{c} \times \sqrt{\left(\mu^{\prime \prime} \varepsilon^{\prime \prime}-\mu^{\prime} \varepsilon^{\prime}\right)+\sqrt{\left(\mu^{\prime \prime} \varepsilon^{\prime \prime}-\mu^{\prime} \varepsilon^{\prime}\right)^{2}+\left(\mu^{\prime} \varepsilon^{\prime \prime}-\mu^{\prime \prime} \varepsilon^{\prime}\right)^{2}}}
$$

As shown in Fig. 7a, the attenuation constant $\alpha$ value of $\mathrm{BaTiO}_{3} @ \mathrm{Ni}-\mathrm{P} / \mathrm{PVDF}$ has increased distinctly within the frequency ranges of $2-11.3,12.7-15.3$, and $16.6-18 \mathrm{GHz}$ compared with that of $\mathrm{BaTiO}_{3} / \mathrm{PVDF}$. In addition, the $\mathrm{BaTiO}_{3} @ \mathrm{Ni}-\mathrm{P} / \mathrm{PVDF} / \mathrm{PANI}$ sample clearly exhibits a higher 


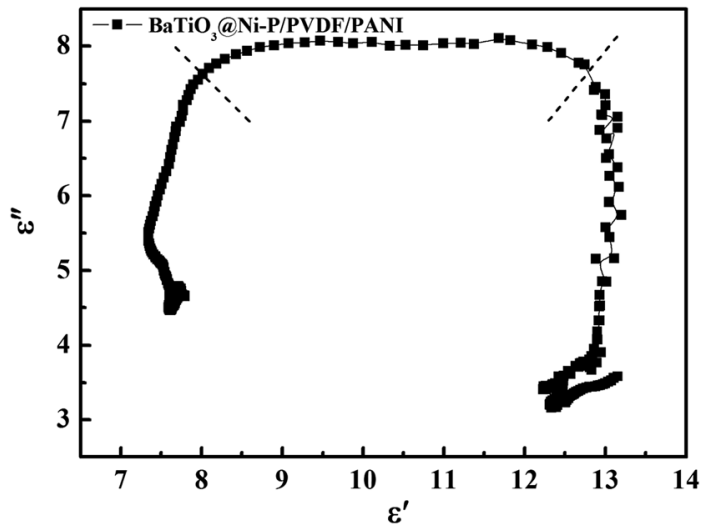

Fig. $6 \varepsilon^{\prime}-\varepsilon^{\prime \prime}$ curve of $\mathrm{BaTiO}_{3} \mathrm{QNi}-\mathrm{P} / \mathrm{PVDF} / \mathrm{PANI}$.

attention constant $\alpha$ than that of $\mathrm{BaTiO}_{3} @ \mathrm{Ni}-\mathrm{P} / \mathrm{PVDF}$ within the frequency range of $8.8-18 \mathrm{GHz}$. Moreover, the impedance characteristic value (Fig. S7 $\dagger$ ) of $\mathrm{BaTiO}_{3} @ \mathrm{Ni}-\mathrm{P} / \mathrm{PVDF} / \mathrm{PANI}$ is close to 1 within the $10-12 \mathrm{GHz}$ range, and thus, the majority of electromagnetic microwave can propagate into the absorber and then be attenuated. ${ }^{41,42}$ RL values are calculated according to transmission line theory as follows: ${ }^{43}$

$$
\begin{gathered}
\mathrm{RL}=20 \log \left|\frac{Z_{\text {in }}-1}{Z_{\text {in }}+1}\right| \\
Z_{\text {in }}=\sqrt{\frac{\mu_{\mathrm{r}}}{\varepsilon_{\mathrm{r}}}} \tanh \left[\mathrm{j}\left(\frac{2 \pi f d}{c}\right) \sqrt{\mu_{\mathrm{r}} \varepsilon_{\mathrm{r}}}\right]
\end{gathered}
$$

where $f$ is the microwave frequency in $\mathrm{Hz}$; $d$ is the thickness of the absorber in $\mathrm{m}$; $c$ is the velocity of light in free space in $\mathrm{m} \mathrm{s}^{-1}$; and $\varepsilon_{\mathrm{r}}$ and $\mu_{\mathrm{r}}$ are the complex permittivity and permeability, respectively.

Fig. 7b shows the RL of the composites with a thickness of 2 $\mathrm{mm}$ within the frequency range of $2-18 \mathrm{GHz}$. The minimum RL value of $\mathrm{BaTiO}_{3} / \mathrm{PVDF}$ reaches $-26.4 \mathrm{~dB}$ at $15.90 \mathrm{GHz}$. However, the valid frequency bandwidth when $\mathrm{RL}<-10 \mathrm{~dB}$ is only $0.75 \mathrm{GHz}(15.46-16.21 \mathrm{GHz})$. With the Ni-P coating, the RL of $\mathrm{BaTiO}_{3} @ \mathrm{Ni}-\mathrm{P} / \mathrm{PVDF}$ improved considerably within the range of $2-15.2 \mathrm{GHz}$, the valid frequency was extended to $3.63 \mathrm{GHz}(9.93-$ $13.56 \mathrm{GHz}$ ), and the minimum RL was $-14.99 \mathrm{~dB}$ at $11.27 \mathrm{GHz}$. For $\mathrm{BaTiO}_{3} @ \mathrm{Ni}-\mathrm{P} / \mathrm{PVDF} / \mathrm{PANI}$, the minimum RL shifted to a high frequency, which reached $-22.56 \mathrm{~dB}$ at $12.72 \mathrm{GHz}$. The valid frequency bandwidth was $4.33 \mathrm{GHz}(11.12-15.45 \mathrm{GHz})$, which is wider than those of other absorbers, such as $\beta-\mathrm{MnO}_{2} /$ PVDF $(2.08 \mathrm{GHz}){ }^{44}$ and ferrite/CNT/epoxy $(3.27 \mathrm{GHz}) .{ }^{45}$ This
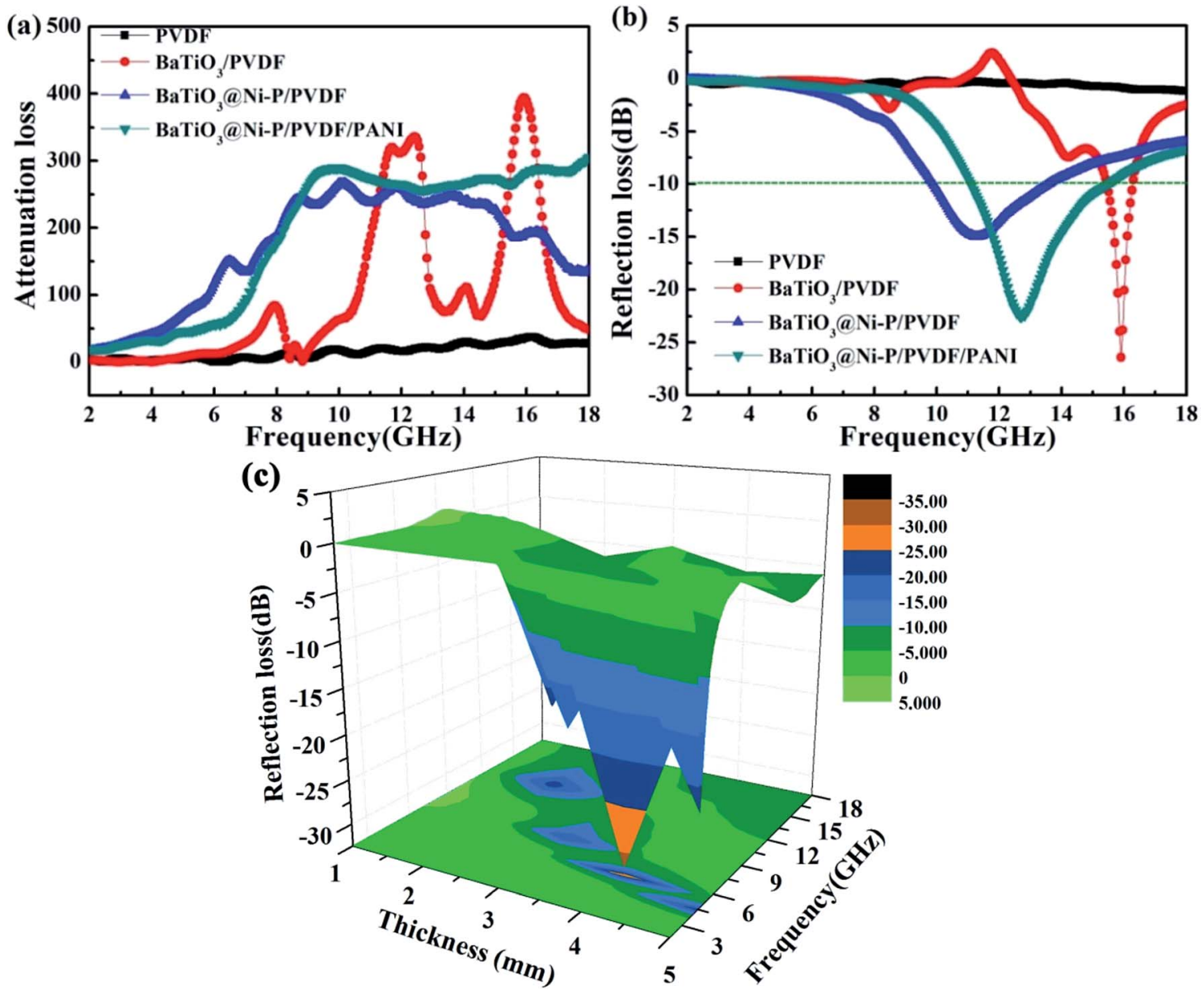

Fig. 7 (a) Attenuation constant $\alpha$ of the samples, (b) reflection loss of the samples with a thickness of 2 mm, and (c) reflection loss of $\mathrm{BaTiO}_{3}$ (aNiP/PVDF/PANI with different thickness. 
result can be ascribed to the aligned PANI, which improves the impedance matching properties of the composites. In addition, multi-interface polarization and synergistic effect are favorable for microwave absorption properties. The comparison of the RL values of the samples indicates that microwave properties improve significantly with a coating of $\mathrm{Ni}-\mathrm{P}$ layer and the growth of aligned PANI.

Fig. 7c shows the microwave absorption performance of $\mathrm{BaTiO}_{3} @ N i-\mathrm{P} / \mathrm{PVDF} / \mathrm{PANI}$ with a thickness of 1-5 mm. The RL peaks visibly shift from a high frequency to a low frequency with increasing thickness. This phenomenon can be explained by the $1 / 4$ wavelength equation $\left(t_{\mathrm{m}}=n c / 4 f\left(\varepsilon_{\mathrm{r}} \mu_{\mathrm{r}}\right)^{1 / 2}\right) .{ }^{46}$ Hence, the absorption frequency range can be tuned by changing the thickness of the composites to satisfy practical application. For comparison, the microwave absorption performances of $\mathrm{BaTiO}_{3} / \mathrm{PVDF}$ and $\mathrm{BaTiO}_{3} @ \mathrm{Ni}-\mathrm{P} / \mathrm{PVDF}$ are shown in Fig. S8. $\dagger$ In addition, $\mathrm{BaTiO}_{3} @ \mathrm{Ni}-\mathrm{P} / \mathrm{PVDF} / \mathrm{PANI}$ films with different filler loadings (30 wt\% and $50 \mathrm{wt} \% \mathrm{BaTiO}_{3} @ \mathrm{Ni}-\mathrm{P}$ powder were loaded onto PVDF) are shown in Fig. S9. $\dagger$ The results indicate that the microwave absorption properties of the composite films can be significantly improved by increasing filler loading. To avoid further increase in the density of films, $70 \mathrm{wt} \%$ filler loading is selected for this study.

The exceptional microwave absorption performance of $\mathrm{BaTiO}_{3} @ \mathrm{Ni}-\mathrm{P} / \mathrm{PVDF} / \mathrm{PANI}$ may originate from the factors illustrated in Fig. 8. On the one hand, the aligned structure of PANI not only works to match characteristic impedance but also provides relatively large specific surface areas that can create additional active sites for the reflection of microwave. Consequently, the propagation path of EW can be extended effectively and a high amount of microwave energy is transformed into heat energy. On the other hand, microcurrent is generated when incident microwave reaches the surface of the conducting PANI. Such electron transmission procedure contributes to microwave absorption properties. Furthermore, natural resonance, dipole

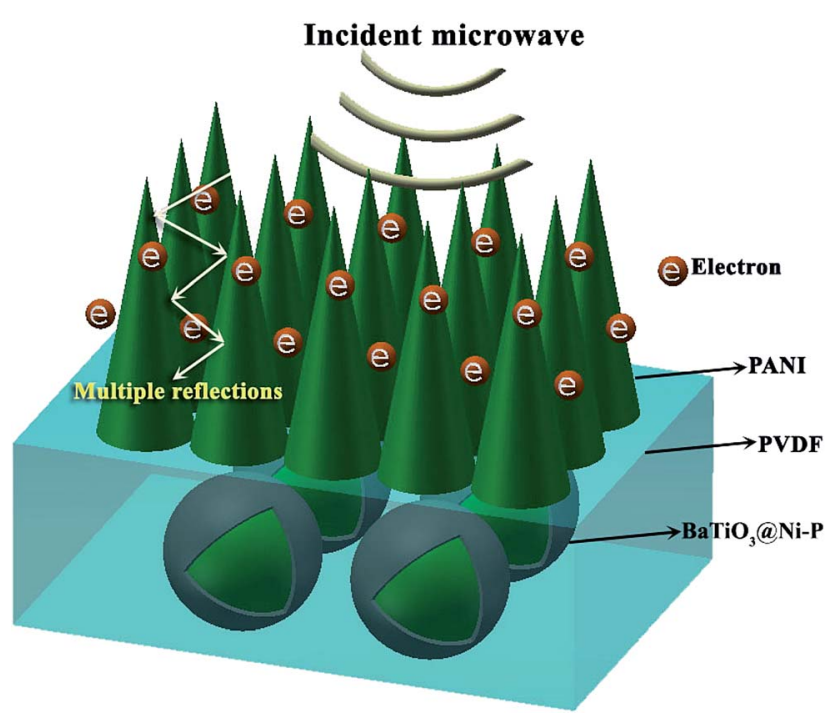

Fig. 8 Schematic illustration of the absorption mechanism of $\mathrm{BaTiO}_{3} \mathrm{aNi}-\mathrm{P} / \mathrm{PVDF} / \mathrm{PANI}$. polarization and strong multi-interface polarization among components are all favorable to microwave absorption properties.

\section{Conclusion}

In summary, $\mathrm{BaTiO}_{3} @ \mathrm{Ni}-\mathrm{P}$ core-shell structure and aligned PANI were synthesized via electroless deposition technology and dilute polymerization process, respectively. Flexible $\mathrm{BaTiO}_{3} @ \mathrm{Ni}-\mathrm{P} / \mathrm{PVDF} / \mathrm{PANI}$ composite films were fabricated through embedding and growing approaches. The $\mathrm{BaTiO}_{3} @ \mathrm{Ni}-$ $\mathrm{P} / \mathrm{PVDF} / \mathrm{PANI}$ composite exhibits exceptional microwave absorption properties within the frequency range of $2-18 \mathrm{GHz}$, which is attributed to the unique structure and the dielectric and magnetic loss. The minimum $\mathrm{RL}$ value reaches $-22.56 \mathrm{~dB}$ at $12.72 \mathrm{GHz}$. When $\mathrm{RL}<-10 \mathrm{~dB}$, the bandwidths are $4.33 \mathrm{GHz}$ (11.12-15.45 GHz) with a thickness of $2 \mathrm{~mm}$. The MAM developed here in this study is promising for industrial-scale applications and in the military field given its strong absorption, broad band and lightweight properties.

\section{Acknowledgements}

This work is supported by National Natural Science Foundation of China (No. 51503183) and Zhejiang Provincial Natural Science Foundation of China (No. LQ14E030010).

\section{References}

1 J. Wei, S. Zhang, X. Y. Liu, J. Qian, J. S. Hua, X. X. Li and Q. X. Zhuang, J. Mater. Chem. C, 2015, 3, 8205-8214.

2 J. Qiu and T. T. Qiu, Carbon, 2015, 81, 20-28.

3 W. Q. Cao, X. X. Wang, J. Yuan, W. Z. Wang and M. S. Cao, J. Mater. Chem. C, 2015, 3, 10017-10022.

4 X. M. Meng, X. J. Zhang, C. Lu, Y. F. Pan and G. S. Wang, J. Mater. Chem. A, 2014, 2, 18725-18730.

5 H. L. Lv, G. B. Ji, X. H. Liang, H. Q. Zhang and Y. W. Du, J. Mater. Chem. C, 2015, 3, 5056-5064.

6 R. L. Ji, C. B. Cao, Z. Chen, H. Z. Zhai and J. Bai, J. Mater. Chem. C, 2014, 2, 5944-5953.

7 R. Qiang, Y. C. Du, Y. Wang, N. Wang, C. H. Tian, J. Ma, P. Xu and X. J. Han, Carbon, 2016, 98, 599-606.

8 S. C. Zhao, Z. Gao, C. Q. Chen, G. Z. Wang, B. Zhang, Y. Chen, J. Zhang, X. Li and Y. Qin, Carbon, 2016, 98, 196-203.

9 W. Choi, G. Yang, S. L. Kim, P. Liu, H. J. Sue and C. Yu, J. Power Sources, 2016, 313, 128-133.

10 F. F. Xu, L. Ma, Q. S. Huo, M. Y. Gan and J. H. Tang, J. Magn. Magn. Mater., 2015, 374, 311-316.

11 Y. J. Li, L. Ma, M. Y. Gan, J. H. Tang, H. F. Hu, C. Q. Ge, L. Yu, H. Huang and F. F. Yang, Mater. Lett., 2015, 140, 192-195.

12 F. Xia, J. W. Liu, D. Gu, P. F. Zhao, J. Zhang and R. C. Che, Nanoscale, 2011, 3, 3860-3867.

13 X. D. Chen, G. Q. Wang, Y. P. Duan and S. H. Liu, J. Alloys Compd., 2008, 453, 433-436.

14 H. L. Lv, G. B. Ji, W. Liu, H. Q. Zhang and Y. W. Du, J. Mater. Chem. C, 2015, 3, 10232-10241. 
15 L. X. Ma, G. Q. Wang, L. D. Liu and B. Y. Li, J. Alloys Compd., 2010, 505, 374-378.

16 Y. K. Liu, Y. J. Feng, X. W. Wu and X. G. Han, J. Alloys Compd., 2009, 472, 441-445.

17 G. Q. Wang, L. X. Ma, Y. F. Chang and C. Liu, Appl. Surf. Sci., 2012, 258, 3962-3966.

18 Y. C. Qing, W. C. Zhou, F. Luo and D. M. Zhu, J. Magn. Magn. Mater., 2011, 323, 600-606.

19 R. G. Yang, J. Magn. Magn. Mater., 2011, 323, 1805-1810.

20 Y. F. Zhu, Y. Q. Fu, T. Natsuki and Q. Q. Ni, Polym. Compos., 2013, 34, 265-273.

21 Q. Q. Ni, Y. F. Zhu, L. J. Yu and Y. Q. Fu, Nanoscale Res. Lett., 2015, 10, 1-8.

22 Y. F. Zhu, Q. Q. Ni, Y. Q. Fu and T. Natsuki, J. Nanopart. Res., 2013, 15, 1-11.

23 X. Zhang, S. Y. Wei, N. Haldolaarachchige, H. A. Colorado, Z. P. Luo, D. P. Young and Z. H. Guo, J. Phys. Chem. C, 2012, 116, 15731-15740.

24 L. Wang, J. F. Zhu, H. B. Yang, F. Wang, Y. Qin, T. Zhao and P. Zhang, J. Alloys Compd., 2015, 634, 232-238.

25 H. B. Yang, T. Ye, Y. Lin and M. Liu, Synth. Met., 2015, 210, 245-250.

26 L. W. Jiang, Z. H. Wang, D. Li, D. Y. Geng, Y. Wang, J. An, J. He, W. Liu and Z. D. Zhang, RSC Adv., 2015, 5, 40384-40392.

27 Y. Wang, X. M. Wu and W. Z. Zhang, Mater. Lett., 2016, 165, 71-74.

28 Y. Z. Wei, G. S. Wang, Y. Wu, Y. H. Yue, J. T. Wu, C. Lu and L. Guo, J. Mater. Chem. A, 2014, 2, 5516-5524.

29 G. S. Wang, X. J. Zhang, Y. Z. Wei, S. A. He, L. Guo and M. S. Cao, J. Mater. Chem. A, 2013, 1, 7031-7036.

30 X. J. Zhang, G. S. Wang, Y. Z. Wei, L. Guo and M. S. Cao, J. Mater. Chem. A, 2013, 1, 12115-12122.
31 X. J. Zhang, G. S. Wang, W. Q. Cao, Y. Z. Wei, J. F. Liang, L. Guo and M. S. Cao, ACS Appl. Mater. Interfaces, 2014, 6, 7471-7478.

32 Y. F. Zhu, L. Zhang, T. Natsuki, Y. Q. Fu and Q. Q. Ni, ACS Appl. Mater. Interfaces, 2012, 4, 2102-2106.

33 Y. Lei, J. Li, Y. Y. Wang, L. Gu, Y. F. Chang, H. Y. Yuan and D. Xiao, ACS Appl. Mater. Interfaces, 2016, 6, 1773-1780.

34 G. W. Chen, Y. Z. Gao and H. Zhang, RSC Adv., 2016, 6, 30488-30497.

35 Q. Liu, S. Gu and C. M. Li, J. Power Sources, 2015, 299, 342346.

36 Q. Y. Yu, Z. X. Zeng, W. J. Zhao, Y. C. Ma, X. D. Wu and Q. J. Xue, ACS Appl. Mater. Interfaces, 2014, 6, 1053-1060.

37 J. J. Xu, K. Wang, S. Z. Zu, B. H. Han and Z. X. Wei, ACS Nano, 2010, 4, 5019-5026.

38 X. F. Liu, Y. X. Chen, X. R. Cui, M. Zeng, R. H. Yu and G. S. Wang, J. Mater. Chem. A, 2015, 3, 12197-12204.

39 D. L. Zhao, X. Li and Z. M. Shen, Mater. Sci. Eng., B, 2008, 150, 105-110.

40 B. Zhao, G. Shao, B. B Fan, W. Y. Zhao and R. Zhang, $R S C$ Adv., 2014, 4, 57424-57429.

41 M. Wang, G. B. Ji, B. S. Zhang, D. M. Tang, Y. Yang and Y. W. Du, J. Magn. Magn. Mater., 2015, 377, 52-58.

42 H. L. Lv, X. H. Liang, G. B. Ji, H. Q. Zhang and Y. W. Du, ACS Appl. Mater. Interfaces, 2015, 7, 9776-9783.

43 M. Fu, Q. Z. Jiao, Y. Zhao and H. S. Li, J. Mater. Chem. A, 2014, 2, 735-744.

44 Y. Niu and X. P. Li, Inorg. Chem. Commun., 2015, 55, 25-29.

45 S. Tyagi, P. Verma, H. B. Baskey, R. C. Agarwala, V. Agarwala and T. C. Shami, Ceram. Int., 2012, 38, 4561-4571.

46 H. Lv, G. B. Ji, H. Q. Zhang and Y. W. Du, RSC Adv., 2015, 5, 76836-76843. 